\title{
Total Design Studio
}

\author{
Massoud S. Tavakoli \\ Kettering University
}

\begin{abstract}
At Kettering University (formerly GMI Engineering \& Management Institute), three conditions reduce the effectiveness of how the engineering design process is taught, especially in capstone design courses: 1) fragmented approach to teaching design, 2) short quarter system (11 weeks of instruction), and 3) alternating work and study terms required by, and essential to Kettering's cooperative education program. As a potential solution, with help from NSF and several interested industrial partners, a design environment called "Total Design Studio" has been set up at Kettering University. Here, all necessary tools for conducting a complete design cycle have been gathered under one roof. Access to CAD software and internet has been provided. A few key technologies, such as rapid prototyping and imaging systems, have been incorporated into the studio as well. As phase one, a capstone design course has been given use of the facilities. The impact of the studio on the students' design output has been qualitatively evaluated. Also, the advantages and the drawbacks of introducing high technology into undergraduate environment have been documented. As phase two, two alternative plans have been developed to expand the design activity from one term to two terms in order to avoid the current time crunch. Of course, both these plans include design activities to be performed over the work-term when the students are at their sponsoring companies. These plans will be evaluated for implementation in the near future.
\end{abstract}

\section{Problem Background}

Kettering University is an ABET accredited, private, not-for-profit and primarily undergraduate degree granting institution. The undergraduate program is a mandatory five-year cooperative education program. Approximately 2,400 students gain up to two-and-three-quarters years of practical work experience with about 600 co-op employers at more than 825 locations. The Mechanical Engineering Department at Kettering ranks within the top five nationally in terms of size and number of graduates. The Mechanical Engineering curriculum is highly laboratorybased with a unique feature where at the beginning of the Junior year, the curriculum branches into five possible tracks called "specialties." Approximately $12 \%$ of the total 180 credits are dedicated to a more in-depth coverage of a sub-field of engineering. The current specialties are Automotive Engineering Design, Medical Equipment Design, Manufacturing Product Design, Machine Design and Plastics Product Design. Each of these specialties culminates into a capstone design course where students are ideally expected to:

1) learn the design process as an "holistic" interdisciplinary activity, and

2) practice the "complete" design cycle from problem definition to prototype development.

Over the years, it was observed that neither of these expectations can be fully realized due to three challenges: 
Challenge I) Fragmented Teaching Process - The physical dispersion of teaching resources around the campus produces a fragmented pedagogical exposure to the design process. For example, the lectures are often delivered in a traditional classroom setting that hinders team activities and creative brainstorming functions necessary for every design process. Moreover, the students develop their designs at computers which are scattered in several computer laboratories. Required background searches must be done at the library. Engineering computations regarding the designed components are usually performed at workstations clustered at yet another location. In our experience, because of the fragmented way we teach design, students do not receive adequate faculty supervision as they practice the design process. We believe that without a close and focused partnership with the faculty, students receive an incoherent design education that limits their understanding of the design process as a multi-level interdisciplinary activity.

Challenge II) Time Constraints - Many schools offer capstone design courses with great depth and multidisciplinary components ${ }^{2-5}$. But a closer look at their curricula ${ }^{1}$ reveals that they accomplish their depth by taking advantage of long semesters ${ }^{2}$ or multiple terms ${ }^{3-5}$. Kettering's capstone design courses must be delivered under a severe time constraint partially caused by our quarter system, and partially due to Kettering's cooperative educational program. Our terms consist of 11 weeks of instruction and one week of final exams. Additionally, all students alternate between work and school sections at the end of each term. While other quarter-system schools can spread their capstone design courses over two or more consecutive terms ${ }^{4}$, lack of continuous access to our students has traditionally forced us to conduct our capstone design courses in one term. Schools with similar discontinuous access to students ${ }^{5}$ have also observed that carrying out a complete design cycle with such a constraint is difficult, if not impossible.

Challenge III) Termination with "Paper" Design - Our capstone design courses end with a "paper" description of a design concept and its relevant computations and computer models. According to a 1994 survey $^{1}$, only $41 \%$ of schools require a functioning prototype in their capstone design courses. We believe that this shortcoming undermines the significant interdependence between manufacturing and design. Like many other schools ${ }^{6}$, the aforementioned time constraint is partially responsible for this phenomenon. However, in addition to more time, some key technologies, such as rapid prototyping, can be utilized to create the capability for a time effective transition from paper designs to 3D prototypes, and even to functional models.

In short, what is missing is an holistic approach to teaching engineering design where all steps of a typical design process are completed in an environment promoting synergy between the various stages of design. In this paper, we describe an ongoing effort at Kettering University focused on dealing with the stated challenges. This effort is supported by NSF grant DUE9851147 and several interested industrial partners. It is stipulated that teaching design can be elevated to a new level of effectiveness by utilizing the technologies described and the curriculum changes proposed herein. 


\section{Proposed Solution}

To effectively teach and practice engineering design, students must develop a "synergistic" design mind-set toward integrating downstream manufacturing constraints with the upstream design specifications. This is difficult to achieve within the present teaching environment where design teaching resources are fragmented. Therefore, a complete design environment called "Total Design Studio" has been created. In this studio, one finds all essential tools needed for carrying out the teaching, the learning and the practice of engineering design. A schematic layout for the Design Studio is presented in Figure 1.

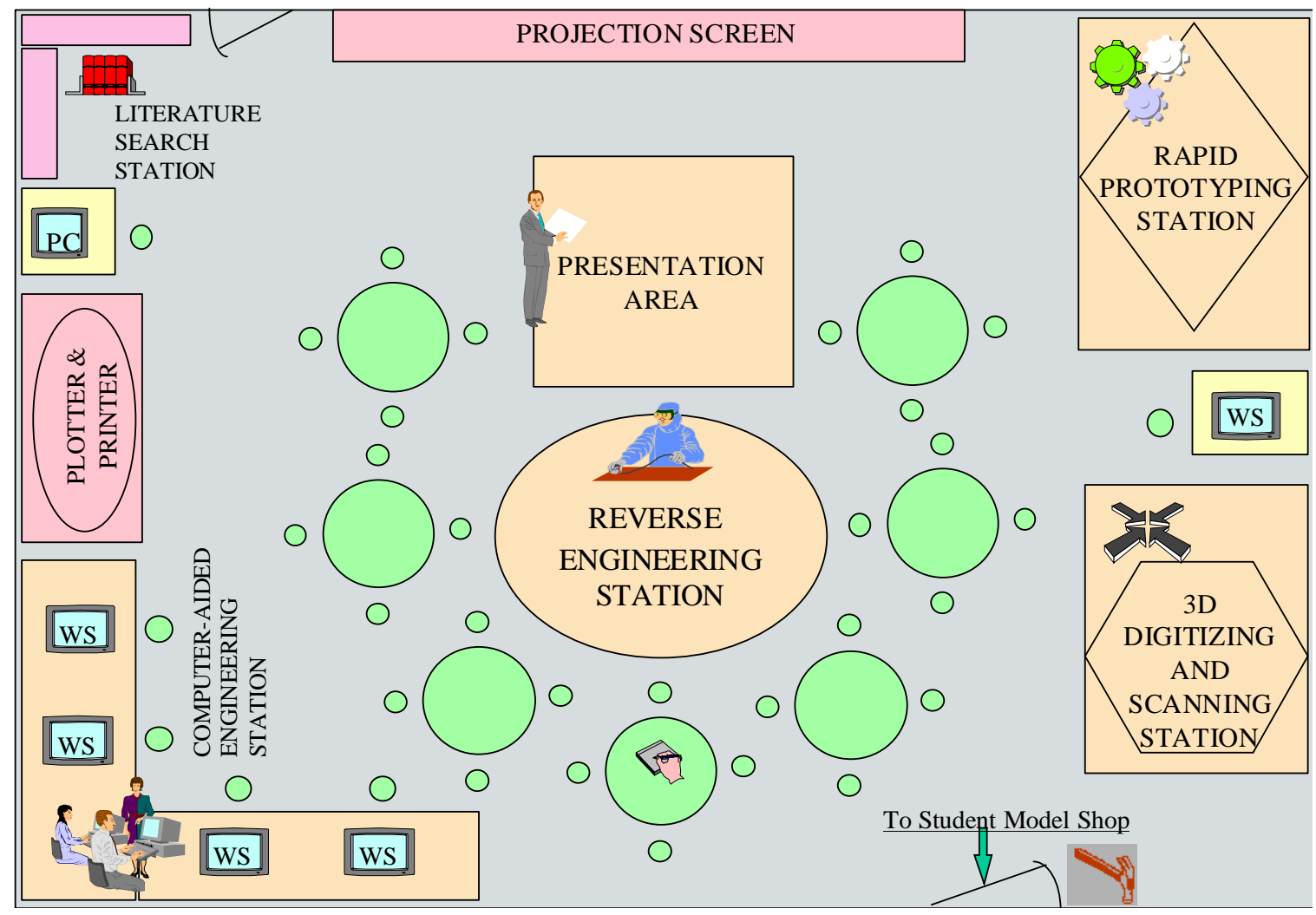

Figure 1: Total Design Studio

The concept we are presenting here is in some ways similar to the "Learning Factory" concept ${ }^{7}$ developed by the Manufacturing Engineering Education Partnership (MEEP) of three universities (Penn State, Univ. of Washington and Univ. of Puerto Rico-Mayaguez), a goverment laboratory (Sandia National Laboratories) and the federal government (ARPA). One of the missions of the Learning Factory is to encourage hands-on physical learning. Kettering University's cooperative educational program already provides ample opportunities for our students to practice engineering at their sponsoring organizations. However, our goal is to provide a well-orchestrated and complete practice of the design cycle for our students before they graduate. 
Furthermore, the Learning Factory is a project of such large proportions that individual schools cannot afford to attempt it without major government support. We believe that the Total Design Studio described herein is an achievable concept by many schools, and its potential for making an impact is high as evidenced by the success of the Learning Factory ${ }^{7}$.

\section{Elements of the Total Design Studio}

The Total Design Studio is comprised of the following stations which together represent the complete cycle of a typical engineering design process.

Teaching Station - The Design Studio is to be used as a teaching environment which facilitates and enhances the learning process of the design cycle. Therefore, the traditional classroom arrangement is replaced with a round-table style of teaching. Instead of individual rows of seats, students are placed in teams seated at round tables which are arranged in a U-shape format. This arrangement places the professor in the middle of the students, and also strengthens designrelated activities such as brainstorming and team problem discussions. The Design Studio is equipped with multi-media presentation equipment. Also, the environment (carpet, furniture, colors, decorations, etc.) is carefully manipulated to enhance comfort and creativity.

Reverse Engineering Station - At the center of the Design Studio, there is a large surface for performing reverse engineering tasks on a product. The instructor can use this station to show how a product is put together, while the students can use it to unravel a product and learn its inner secrets. The central location of the reverse engineering station provides equal visual access for the entire class.

Literature Search Station - A small library is placed in the Design Studio. This library has literature such as product catalogues and design handbooks which are valuable to the design process. At the same time, this station is connected to the internet so that broader on-line searches can be performed. The students are encouraged to use the internet to communicate with other design engineers and vendors worldwide, as well as perform extensive search for patents.

Computer-Aided Engineering Station - This station serves two parts of a typical design cycle. First, it serves as a modeling station where design ideas are transferred to engineering drawings and computer models. Second, engineering computations required for detailed design of a product are performed here. This station is also equipped with an appropriate plotter and color printer.

Rapid Prototyping Station - One of the major impacts of the Design Studio on our current design teaching process is realized through the use of rapid prototyping (RP) technology. Here, students gain the ability to generate 3D models of their paper designs. This greatly enhances the students' understanding of their designs. Also, the RP technology creates the possibility for producing "functional" prototypes by having metal castings of the RP parts made either within Kettering's foundry or at an off-site location.

3D Imaging Station - This station consists of a laser scanning system used for reverse engineering activities. Students develop computer models of actual manufactured parts using the 
imaging system. These computer models can then be redesigned graphically and sent to the rapid prototyping station to get duplicate models to be used for further modification and/or reproduction.

Model Shop - In addition to the design stations, the Design Studio is located adjacent to the existing Student Model Shop. The students have access to machinery required for making additional parts to merge with a rapid prototyped model, or they can produce a simple model using the machinery in the model shop. This invariably increases the students' understanding of the crucial link between design and manufacturing processes.

\section{Proposed Curriculum Changes}

As cited previously, schools that successfully implement the complete design cycle do so because either: a) they have a semester system, or b) they spread their capstone design experience over two or more successive terms. Given Kettering University's cooperative education system, we are faced with the challenge of having access to our students for only three months (11 weeks of instruction) at a time before they have to return to their work sessions for the following three months. This has put severe time limitations on our capstone design courses, which are currently all single-quarter courses. That is why most of our design projects end with a CAD model.

Undoubtedly, the Design Studio has and will continue to give Kettering students the technological tools to create 3D models of their designs and also engage them in high-end design activities. One such activity would be to reverse engineer an existing product (design) by utilizing the imaging system, redesign the part using CAD, and finally produce a rapid prototype of the modified design. However, the Design Studio by itself will not completely compensate for our time constraints. To address this issue, two alternative curriculum changes have been proposed.

Proposal One - It is proposed that the capstone design courses be spread over two nonconsecutive terms separated by one work term (total of nine months). The first course, worth two credits, will be offered to Senior-II students (Kettering has three classes of seniors due to the 5year program). The students will be expected to perform the first few phases of the design process, from problem identification and background search through preliminary design concept development.

The second course, also worth two credits, will be offered to the same group of students who will by now be in their Senior-III terms. They will finalize the preliminary design concepts, perform needed engineering analysis, and develop functional prototypes of their designs. All of these activities, of course, will be carried out in the Design Studio where as described earlier, a synergistic approach to design is possible due to close interaction between students and faculty who serve as design "coaches."

Finally, it is proposed that the work term between Senior-II and Senior-III terms be used for a low-level background search on the design projects. Each design team will be expected to submit two progress reports to the faculty via email and a web-site where they continuously collect 
research information until they are back on campus. In this manner, the faculty and all design team members are forced to stay in touch using multi-media tools.

This proposal accomplishes an expansion of the capstone design activity without burdening the curriculum with any additional credit hours. This is achieved by removing the time pressures commonly caused by delays in acquiring needed information and parts from suppliers. Other than logistical and administrative problems, one drawback of this proposal is that it extends a three month project into nine months, possibly deterring some industrial sponsors from submitting meaningful projects.

Proposal Two - It is proposed that the capstone design course remain a one-term four-credit course offered to Senior-III students only. However, the projects will be managed over two successive terms such that two successive groups of students will be involved with the same project. It is envisioned that the first group will be exposed to product design concepts by carrying the projects from problem identification phase through the detailed design phase. The second group will practice product realization concepts by developing the design concepts into functioning prototypes complete with a business plan that includes a manufacturing and possibly a marketing plan.

This proposal allows for termination of a project at the end of the detailed design phase should a sponsoring company see no need for the product realization phase. Depending on the reasons for termination, the second group of students can restart the project from scratch, or start a new design project while other students carry out product realization of other projects that have generated their respective sponsors' interest. One drawback of this proposal is that it exposes the students to experiences dealing with either product design or product realization, not both.

\section{Conclusions}

Since the inception of NSF grant DUE-9851147 in July 1998, the infrastructure of the Total Design Studio has been put in place delivering the vision portrayed in Figure 1. The studio has been functioning as a center for design activity for a number of courses. The layout has been effective in breaking up the routine of passive learning commonly occurring in traditionally arranged classrooms. CAD workstations and PC's have made it possible for meaningful exchange of opinions between students and professors during design review sessions.

Although it took nearly a year to integrate the rapid prototyping device into two capstone courses, its addition has been a tremendous help in ensuring that the design intent has been indeed captured within the CAD models. This technology has been useful in pointing out typical "rookie" mistakes made by design students who have a tendency to overlook manufacturability and assemblability issues in their designs. At the same, under the current time limitations, rapid prototyping has been the only source of transforming paper designs into physical models.

More importantly, the rapid prototyping capability has created the ability to take a physical model of a design to the project sponsors (customers) as a part of the design review activity. An example of this type of communication occurred in a recent Medical Equipment Design capstone course where prototypes of student designs were taken to the sponsoring hospital and presented 
to the medical residents during their weekly rounds. A significant level of design feedback was generated based on these prototypes.

Although the level of training needed to safely operate a rapid prototyping machine is not out of reach of any undergraduate engineering student, the time needed to acquire sufficient training is not available within a typical capstone course. Therefore, this technology has been operated by the professor or an assistant with the students observing and learning about rapid prototyping. The same is true of the imaging system that is currently being installed in the Design Studio.

Finally, Kettering University is currently undergoing a comprehensive curriculum restructuring process. One of the two alternate curriculum changes proposed in this paper will be a part of this process, but that has to be delayed until the new curriculum is put in place in the year 2001 .

\section{Bibliography}

1. Todd, R.H., Magleby, S.P., Sorensen, C.D., Swan, B.R. and Anthony, D.K. A Survey of Capstone Engineering Courses in North America. Journal of Engineering Education, April 1995.

2. Mendelson, M. and Caswell, C. Integrated Product Development in the Classroom. ASEE Annual Conference Proceedings (session 2563), 1997.

3. Latino, C.D. and Hagan, M.T. A Unique Capstone Design Program. ASEE Annual Conference Proceedings (session 1626), 1996.

4. Byerley, A.R. and O'Brien, E. Techniques for Advising Undergraduate Students on Senior Engineering Design Projects. ASEE Annual Conference Proceedings (session 1275), 1996.

5. Gold, F.M. and Bausch, J.J. Teaching Fixturing for Manufacturing Processes within the Learning Factory between Worcester Polytechnic Institute and Pratt \& Whitney. ASEE Annual Conference Proceedings (session 1463), 1996.

6. Aldridge, M.D. Cross-Disciplinary Teaming and Design. ASEE Annual Conference Proceedings (session 0230), 1996.

7. Lamancusa, J.S., Jorgensen, J.E. and Zayas-Castro, J.L. The Learning Factory - A New Approach to Integrating Design and Manufacturing into the Engineering Curriculum. Journal of Engineering Education, April 1997.

\section{Author Biography}

Massoud S. Tavakoli is a professor of Mechanical Engineering at Kettering University. He received his Ph.D. and M.Sc. from the Ohio State University, while his B.S. is from Louisiana State University. Dr. Tavakoli is a registered Professional Engineer, and has been teaching engineering design over the past 12 years. He is responsible for the development of the Medical Equipment Design specialty at Kettering University as well as an introductory sophomore level design course that has received honorable mention for curriculum innovation from the American Society of Mechanical Engineers.

\section{Acknowledgements}

The creation of the Total Design Studio would not have been possible without the financial support from: NSF grant DUE-9851147, Hougen Manufacturing (Flint, MI), Rapistan-Demag (Grand Rapids, MI) and Biomet ( Warsaw, IN). 